\title{
MISCELÁNEA
}

\section{PEDRO ESPINOSA Y GÓNGORA}

\author{
Antonio Carreira.
}

Con este mismo título en orden inverso publicó la gongorista americana E. J. Gates su primer estudio acerca de la influencia de Góngora en poetas del Siglo de Oro, donde ampliaba hasta casi 50 la inicial docena de ejemplos de mimetismo espinosiano recogidos en su tesis doctoral ${ }^{1}$. La figura del poeta Pedro Espinosa (Antequera, 1578 - Sanlúcar, 1650) es bien conocida desde que hace un siglo $\mathrm{F}$. Rodríguez Marín comenzó a prestarle atención, al heredar del Dr. Quirós el encargo de anotar y reimprimir sus Flores de Poetas Ilustres (Sevilla, 1896), trabajo que fue seguido de la biografía (Madrid, 1907) y la edición de sus Obras (Madrid, 1909). Muy poco es lo que se ha podido añadir desde entonces en el plano biográfico, bibliográfico y documental a lo averiguado por el Bachiller de Osuna ${ }^{2}$ - autor más saqueado que Cádiz, ahora que los afanes curriculares y el arrobo ante la producción propia no dan lugar a reconocer méritos ajenos ${ }^{3}$. Pendiente quedaba, en cam-

1 "Góngora and Pedro Espinosa”, Philological Qwarterly, XII, 1933, págs. 350-359. La tesis de la autora, The Metaphors of Lwis de Góngora, es del mismo afio (Philadelphia, 1933). En sucesivos trabajos fue estudiado el gongorismo de Calderón (1937), Paravicino (1938), Sor Juana (1939), Fonseca Soares (1941), Pantaleón, Tamayo Salazar y Miguel de Barrios (1952).

2 Excepción son dos artículos de F. López Estrada, “Documentos sobre Pedro Espinosa (1613). Fundación de las capellanías de Nuestra Sefiora de Gracia en Archidona, y de la Magdalena, en Antequera", Estudios de literatura y arte delicados al profesor Emilio Orosco Diaz, Granada, 1979, II, págs. 287-295, y "Una relación sobre las previsiones de Cádiz ante el ataque inglés de 1625, atribuible a Pedro Espinosa", Glosa, n 2 (1991), págs. 175-196. "Una nueva relación poética (del afio 1624)", publicada por J. C. de Torres (Revista de Literatura, LIV, n. 108, 1992, págs. 667-708), viene a dar otra perspectiva, en verso y anónima, del célebre presente enviado por el Duque de Medina Sidonia a Felipe IV, y descrito por Espinosa en el Elogio al Retrato (1625).

3 Es, en efecto, más sabido que admitido que el Espinosa de Rodríguez Marín constituye una inapreciable mina de información sobre la escuela antequerano-granadina, y, en general, sobre los poetas andaluces del siglo xvIr, como lo es también para los del xvi su monumental Barahona de Soto (Madrid, 1903), y lo son otros muchos trabajos 
bio, el estudio de los textos, pues Rodriguez Marin, contra su costumbre, los entregó al lector sin otras notas que unas "Adiciones y enmiendas" a su biografía, seguidas de un glosario de voces donde predominaban las aún no acogidas por el diccionario académico. Y poco es también lo que llegaría del poeta antequerano al público no especializado: de las Flores se estamparon contados ejemplares, la biografía y las Obras pasaron pronto a ser pieza de coleccionista ${ }^{4}$; Rodriguez Marin hacía votos por que alguien vulgarizara en edición económica los edificantes tratados de Espinosa, pero sus palabras no suscitaron mayor eco. En 1923 el Marqués de Laurencín publicó El perro y la Calentura en el Boletín de la Real Academia de la Historia; en 1933 editó J. M. ${ }^{a}$ de Cossío una selección de la poesía de Espinosa en la revista Cruz y Raya, y en 1935 la Fábula del Genil, con breve prefacio y en tirada de bibliófilo; en $1946 \mathrm{~J}$. R. Morales imprimió en Chile una escueta antologia poética, y en 1950 A. Canales y J. A. Muñoz Rojas publicaron en Málaga una Soledad de Pedro de Jesís, de circulación muy restringida. Con algo de retraso se conmemoró el tricentenario de su muerte en el Homenaje a Pedro Espinosa (Sevilla, 1953), que contiene varios trabajos de interés, entre ellos parte de la tesis de A. Lumsden, otros de J. A. Muñoz Rojas y R. Molina, y una "Justificación literaria de Pedro Espinosa" a cargo del profesor F. López Estrada, especialista en temas y autores antequeranos, quien traza en el prólogo un estado de la cuestión, con la correspondiente bibliografía.

Muchos años habían de pasar hasta que el propio López Estrada reeditara las Poesías completas de Espinosa en la vieja colección de Clásicos Castellanos ${ }^{5}$, y la Obra en Prosa, en la nueva de Clásicos Malagueños ${ }^{6}$. Am-

suyos: entre ellos el dedicado a dofía Cristobalina Fermández de Alarcón, posible musa de Espinosa (BRAE, VII, 1927, págs. 368-423). Lo que pueda haber de trasnochado en el positivismo, el casticismo y el antigongorismo de Rodríguez Marín no invalida en absoluto el tino de muchas de sus intuiciones y la solidez de sus pesquisas por bibliotecas y archivos de protocolos de media España. Pese a todas sus limitaciones de método y época - señaladas por J. Lara Garrido respecto a Barahona en su ed. de Las lágrimas de Angélica (Madrid, 1981), y ahora respecto a B. del Alcázar en su estudio sobre el Cancionero de Rodrigo Fernández de Ribera (Voz y Letra, III, 2, 1992)-, nuestro conocimiento de la poesía y de los poetas andaluces del Siglo de Oro le debe acaso más que a nadie.

- Según la bibliografía que da López Estrada en Obra en prosa, pág. 456, el Pedro Espinosa de Rodríguez Marín fue objeto de una edición facsímil en Amsterdam: Philo Press, 1975.

- Madrid: Espasa Calpe, 1975; lviii + 213 págs. López Estrada afiade un gracioso soneto (pág. 32), que no figura en la ed. de Rodríguez Marín, procedente del ms, de la British Library. Y omite el dato menor de que en el Cancionero Antequerano se atribuyan al también antequerano Luis Martín de la Plaza dos poemas indudables de Espinosa: el son. "Estas purpúreas rosas que a la aurora" (pág. 18) y la "Canción a San Acacio" (pág. 58), mientras que se adjudica a Espinosa otro de Quevedo (cf. infra).

- Málaga: Diputación Provincial, 1991; 485 págs. Edición enriquecida con la Relación de los preparativos ante el ataque inglés a Cádiz citada en la nota 2 (págs. 445453), y con el cuadro de Zurbarán sobre la defensa de la ciudad (frente a pág. 314), don- 
bos libros recuperan asi para el lector común la obra de un poeta y prosista sin duda menor, pero que como antólogo estuvo en el centro de irradiación de nuestra mejor poesía lírica, fue amigo de Góngora y de Quevedo, y vivió protegido por el mayor mecenas de su tiempo, cuya casa vio lucir con brillo incomparable, y venirse luego abajo en forma estrepitosa. De todo ello había tratado Rodríguez Marín, con multitud de detalles que López Estrada recoge, extracta y sistematiza, completando los estudios literarios de la obra espinosiana dejados en ciernes por su antecesor.

No es, por tanto, de tales hechos ni de las modernas reimpresiones de lo que ahora queremos hablar, sino del aspecto enunciado en el título, que apenas toca Rodríguez Marín, desarrolla poco E. J. Gates, y asume sin cambios López Estrada. Es habitual entre los estudiosos recordar las censuras y cuchufletas con que Rodríguez Marin pretendia estigmatizar a Góngora y a su escuela, y acaso también seguirle la corriente a su maestro don Marcelino, quien del vate cordobés solo toleraba la poesía mal considerada fácil de romances y letrillas. Expresiones como "jerigonza poética", "vana hojarasca", "tenebrosas lucubraciones", "vanas hinchazones", "grave mal del culteranismo", "funesto contagio", “odiosa plaga", "aborrecible ponzoña" (Pedro Espinosa, págs. 368 y 386) harian hoy sonreír si no fuera tan triste y sintomático que un país, por boca de sus mejores intelectuales, haya podido pasar dos largos siglos empecinado en denigrar a su mayor poeta. Tampoco estaba al alcance de Rodriguez Marin, respecto a la literatura áurea, rechazar el dogma dieciochesco de la división en escuelas culterana y conceptista, falacia que cien años después tiene aún predicamento entre quienes se dedican a la industria textil copiando rancios dechados. $\mathrm{Y}$ así escribe que "más bien ... se arrimó Espinosa a la escuela conceptista ...; que él no desatendió, por cuidar con demasia de lo más exterior de la forma, el fondo de sus producciones" (op. cit., pág. 386), y que "distó mucho de figurar entre los desaforados secuaces del gongorismo" (ibid., pág. 367); de todas formas, como "no se libraría por completo del contagio, enfermaría levemente de tal enfermedad, de la cual, porque todos los pulmones respiraron aire inficionado con sus gérmenes, casi nadie se eximió del todo" (ibid., pág. 386), al fin es forzoso reconocer que "hay dos Espinosas: el anterior y el posterior al pernicioso influjo" (ibid., pág. 368):

Así tiene satisfactoria explicación el que, al par que Espinosa escribía las composiciones gongorescas antes mencionadas, escribiese sus fáciles décimas, llenas de nobles y hermosos pensamientos, Contra la ansiosa cudicia, y su largo y primoroso romance $A$ un avariento, en las cuales poesías no hay nada que sepa a Góngora (ibid., pág. 387).

de podrían estar representados el Duque de Medina Sidonia y su cronista. Al tiempo que la prosa veía también la luz el facsímil de las Flores (Madrid, 1991). 
En efecto, ambos poemas son poco gongorinos, pero también ahí los consabidos gérmenes hicieron de las suyas, contra lo que opina don Francisco. Porque cuando Espinosa aconseja en las décimas: "No, cual gusano de seda, / sea tu cárcel tu sudor" (ed. cit., pág. 87), no hace sino resumir el comienzo de un romance de don Luis:

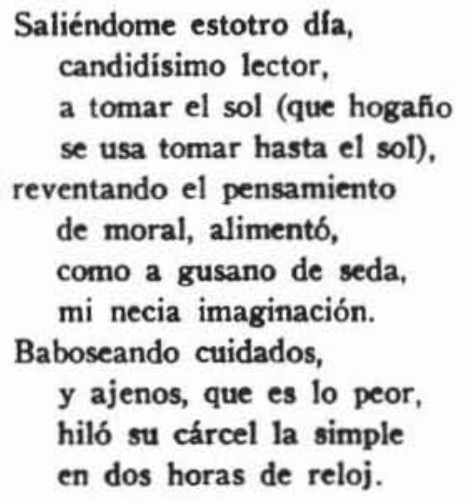

$\mathrm{Y}$ cuando en el Romance $a$ un avariento incluye esta cuarteta: "Nunca vi avariento rico, / si no es de sospecha y miedo: / sepultura de sí propio / con facultades de muerto" (ed. cit., pág. 92), los dos últimos versos se limitan a calcar la suspensión de Píramo ante las huellas de Tisbe, en el romance más ponsoñoso del mismo Góngora (que brinda también un terminus a quo para fechar el poema de Espinosa):

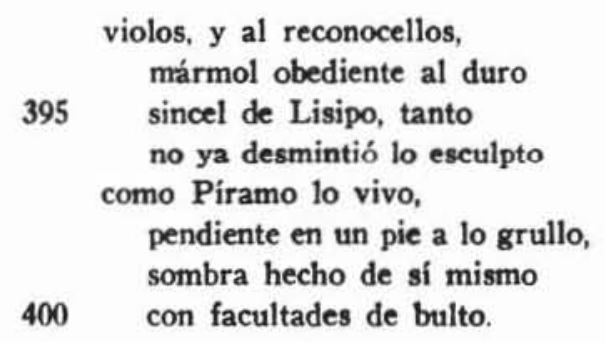

Si esto ocurre en los poemas "incontaminados", no sorprenderá que en los otros asome Góngora a cada paso. Espinosa probablemente se hubiera divertido mucho con los esfuerzos de su biógrafo por exculparlo de lo que para él constituía un ideal. Porque en nuestra historia literaria no se ha dado otro caso de escritor que haya suministrado a sus lectores tantos estilemas, tantos modelos de dicción ajustada y ejemplos de perfección en el concepto. Más de un siglo de literatura riquísima quedó impregnado en tales elementos, anegado bajo ellos, como si de pronto la lengua castellana, que sesteaba tranquila en la altura alcanzada la centuria precedente, sufriera una inundación de imágenes inusitadas, acuñaciones verbales y hallazgos rítmicos de fuerza insos- 
pechada, que la dejó irreconocible y alcanzó a los rincones más apartados e impermeables. Las consecuencias no siempre fueron benéficas: la oratoria sagrada lo pasó mal, el teatro no las tuvo todas consigo, e incluso se ha querido relacionar la llamada "desaparición" de la novela moderna con el estado en que quedó la prosa castellana tras la crecida ${ }^{7}$. Las imitaciones y las influencias, como no podia ser menos, responden a su propia dialéctica.

Góngora no abre sino que cierra, espléndidamente, una época de gran poesía española — como un siglo más tarde J. S. Bach cerrará más que abrirá, asimismo genialmente, otra de gran música germánica. Seguir sus pasos para llegar más allá era muy difícil ; apartarse de ellos o ignorarlos era imposible, como lo hubiera sido, por ejemplo, intentar escribir teatro sin referirse a Lope. Góngora concentra en sí dos mil años de poesia occidental: griega, latina, medieval, popular, cortesana, italiana e italianizante. En su línea solo se podia aspirar a hacer figura de epígono, precisamente porque él era la culminación y cualquier movimiento había de significar descenso. Tomar distinto rumbo requería partir de muy abajo, como hicieron los poetas neoclásicos componiendo figura aún más lamentable. A Bach le sucedió, no le siguió, Mozart, que sí inauguró una nueva época en la música, aquella en que las formas arcaicas dejan paso a la forma sonata, correlato exacto de la forma novela, las cuales van a sefiorear sus respectivas artes desde fines del siglo xvirr hasta bien entrado el xx. A Góngora, en cambio, le siguieron muchos pero no le sucedió nadie. $\mathrm{El}$ caso de Quevedo es, en ese sentido, patético, porque teniendo madera de pionero llegó tarde a casi todo. Debe lo más valioso de su obra a su genio y a su esfuerzo antes que a tópicos como el desengaño, el barroco o el neostoicismo, y sin embargo su lírica no es siquiera concebible sin la del cordobés. Poetas como Espinosa en España, Noronha en Portugal o Matos en Brasil podian sentirse más próximos a Quevedo por talante o pensamiento, pero a la hora de escribir, a quien volvían sus ojos era a Góngora, al involuntario maestro de su tiempo.

Aunque no es fácil establecer un orden cronológico en la poesía de Espinosa (si se excluyen los termini ad quos de los 19 poemas impresos en Flores, y los termini a quibus que pueden proporcionar las citas de poemas gongorinos fechados), su admiración por don Luis ha de ser muy temprana, visto el predominio que como antólogo le concede. Se puede postular que haya tenido acceso a su restante obra mucho antes de que circulara impresa. De 1607 por lo menos data la amistad de don Luis con el Conde de Niebla, dedicatario del Polifemo en 1612, Duque de Medina Sidonia y amo de Espinosa desde 1615. De unas maliciosas palabras de Morovelli transcritas por Rodríguez Marín se

7 J. F. Montesinos, Introducción a una historia de la novela española en el siglo XIX, Madrid, 19723, pág. 2. 
desprende que no solo el Duque sino también su cronista era aficionado a Góngora :

Así, señor, vi a V. E. muy bien retratado, pero no sé si está tan bien historiado en los escritos de algunos; que para saber esto como se debe son menester grandes estudios, con mucho conocimiento de los autores de la antigüedad, mucha noticia de las buenas letras, y esta no la dan las obras de D. Luis de Góngora, ni sus Soledades, porque es quedarse muy con ellas (P. Espinosa, pág. 293).

Este opúsculo es de 1631, cuando solo existia la edición de Vicuña, apenas difundida a causa de la censura. Cobra asi fuerza la hipótesis de R. Jammes - no recordada en los últimos estudios - respecto a que el ms. gongorino 4.269 de la Biblioteca Nacional, uno de los mejores entre los integri, se habria tejido en el entorno del Duque de Medina Sidonia, posiblemente bajo la supervisión de su mismo capellán, Pedro Espinosa ${ }^{8}$. Pero aun sin tal conjetura, la obra de Góngora se reprodujo en una medida bastante mayor de lo que hoy podemos detectar, y para un poeta andaluz, amigo desde joven de don Luis y en buenos términos con muchos otros, no debió suponer ningún problema mantenerse al tanto de ella.

Sea como fuere, Espinosa, si se descarta la empresa de las Flores, y sobre todo a partir de su ordenación sacerdotal, no parece haber aspirado a más que componer poemas esporádicos, piadosos o de circunstancias, o a cumplir sus deberes de panegirista con opúsculos que pudiesen complacer al pequeño círculo del Duque y sus amigos. Prueba de que no perseguia mayor originalidad son la repetición de fórmulas y pensamientos, la inserción de páginas de Quevedo en El perro y la Calentura, y el engaste de frases ajenas, entre las que las gongorinas constituyen abrumadora mayoria. La sentencia "tanto harta, señor, una fuente como un río" la pone en boca del Conde de Niebla para responder en cierta ocasión a su suegro, el Duque de Lerma (Elogio al retrato, Obra en prosa, ed. cit., pág. 265). Algo variada, aparece en el romance a un avariento ("que no harta más la sed / un río que un arroyuelo", ed. cit., pág. 91). Pues bien, tampoco es suya: Rodriguez Marín la ha localizado en un soneto de Medrano ( $P$. Espinosa, pág. 225). En El perro y la Calentura, donde es excusado buscar la menor coherencia narrativa, Chorumbo cuenta la siguiente anécdota:

- Les Langues Néo-Latines, n. 153 (1960), pág. 86. El argumento principal es que en epigrafes de poemas dedicados a don Miguel de Guzmán, hermano del Duque, una de las manos que apostillan el códice ha añadido: "mi sefior". El ms. consta de un indice alfabético +568 folios divididos en dos numeraciones, 1-200 y 1-368, con letra clara y uniforme. Contiene poemas de hasta 1625 , pero puede muy bien ser el resultado de ordenar y copiar cuadernillos reunidos a lo largo de muchos af́os. 
A mi me aconteció levantarme de noche a estudiar, y, por tomar una vela, tomar un pedazo de longaniza, y llegar a soplar al fuego donde estaba el gato echado, y, como le relumbraban los ojos, llegarles la longaniza, y echarle el diente y dar a huir con ella y dejarme espantado y sin estudiar. Ojo avizor, que es el diablo el gato, etc. (Obra en prosa, pág. 184).

Pero la tal anécdota, de la que nada dicen los editores, deriva de otra impresa setenta años antes, entre las más conocidas y sabrosas del Dr. Laguna:

No puedo tener la risa siempre que me acuerdo de vn moso torpe y dormilonazo que tuue siendo estudiante en Paris, el qual vna mañana tres horas antes del día, queriéndome encender candela, se fue derecho al hogar, adonde estaua vn gatazo sobre el rescoldo de la ceniza con los ojos abiertos: los quales pareciéndole a él ser dos ascuas ardientes (porque ansí reluzen y centellean de noche), le plantò en el vno dellos de medio en medio vn palillo de açufre: por donde súbito le saltó el fiero animal al rostro y le rascuñò toda la cara, no sin grandes gritos del azemilonazo, que quedó por vn tiempo attónito, creyendo firmemente que houiesse sido el demonio (nota al Dioscórides, lib. V, cap. LXXXII, ed. Salamanca, 1563, pág. 550).

Incluso es sospechoso el episodio biográfico del Conde de Niebla (Elogio al retrato, Obra en prosa, págs. 249-251), que no parece estar documentado; Rodríguez Marín transcribe el relato del mismo incluido por fray Pedro Beltrán en La Charidad Guzmana, VII. Según Espinosa, cuando su amo tenía veinte años, "viniendo de Huelva a Sanlúcar en un barco que habia traspuesto de otros tres que le seguian, halló una galeota de valientes piratas turcos". El Conde iba solo con seis criados, algunos de ellos músicos, y aunque el arráez quiso huir, le arrebató el timón, abordó a la galeota trepando por un remo, $y$

al sol de Niebla se escureció la Luna, helándose la sangre de los turcos... El valentísimo Conde les dio tan furiosa priesa que les turbó el uso de la pólvora, les agotó las saetas, los palos y las piedras, y hasta melones le tiraron. Al fin, gloriosamente, a todos los rindió, a muchos hirió y mató, y con veinticuatro de ellos entró triunfando en Sanlúcar, los cuales envió presentados, vestidos de rica librea, a su Majestad (ibid., pág. 251).

Cun razón advierte López Estrada en el detalle de los melones un "contrapunto de humor" que acaso divertiría al Duque. Porque el relato, con melones o sin ellos, no hay por dónde cogerlo, y menos cuando se encuentra una proeza similar atribuida mucho antes a don Juan de Austria:

Llégale la nueva, estando cenando en Castilnovo de Nápoles, que la galera Renegada, nuestra, con setenta turcos, habiendo muerto cuatro cristianos que había en ella de guarda, se le había levantado e iba la vuelta de Africa. Pues dado tan repentino rebato, deja don Juan la mesa y la vianda, y sale precedido 
de dos pages con hachas, diciendo: " $i$ Soldados, apriesa, apriesa, que se nos ha levantado una galera!" Métese en su Real con hasta una docena de infantes en una noche escura, que con la priesa que llevaba no pudo hallar más; promete a nuestros forzados gran premio; van al momento allá, y a seis leguas que le llevaban de ventaja, alcánzanla junto a las bocas de Capria. Aborda y salta nuestra poca gente en ella, y el primero el sargento Rivera, un buen soldado, y comiençan a andar con los turcos a cuchilladas, que si entendieran estos cuán pocos eran los cristianos, que les engañó la soberbia galera Real, a los pocos hicieran pedazos tantos como ellos eran. Así doce españoles vencieron y mataron a cien turcos libres, desesperados y ofendidos (L. Zapata, Miscelónea, Madrid, 1859, págs. 360-1).

Por cierto que los editores omiten mencionar, respecto a la juvenil hazaña del Conde de Niebla, que sirvió de argumento a La galeota reforzada, comedia de Francisco López de Zárate conservada en autógrafo 9.

Volviendo, pues, a nuestro asunto, vamos a terminar con la enumeración de los lugares gongorinos aún no señalados en la obra de Espinosa, siguiendo el orden topográfico de las modernas ediciones ${ }^{10}$. En la Epistola al licenciado Antonio Moreno se encuentran estos versos: "Mas asi goce la presencia tuya, / que mil veces culpé las horas raudas, / porque a mi parecer habian trocado / volantes plumas por pesado plomo" (ed. cit., pág. 15); Góngora usa la imagen para indicar la impaciencia del príncipe Felipe, que en 1620 culpa la lentitud de las horas que faltan para la consumación de su matrimonio: "A ellos —dice-, soldados, / embestidlos, advirtiendo / que láminas son de pluma / cuantas mienten el acero... / Las horas vuelen", etc. (rom. 82); lo mismo hace en un soneto de ese año: "Fileno en tanto, no sin armonía / las horas acusando..." (n..$^{\circ} 356$ ). En dicha epistola, v. 83, injiere también Espinosa el v. 405 de la primera Soledad: "el padre de las aguas Oceano". El soneto a Jesucristo en la cruz (pág. 39) comienza con varias frases de infinitivo que sirven de sujeto a un verbo ("Desplegar como un velo en los coluros ... / pequeña gloria fue ..."); no es otra la estructura del que Góngora había dedicado al mismo asunto poco antes de imprimirse en las Flores ("Pender de un leño ... / bien fue heroico hecho", n. ${ }^{\circ} 265$ ). A veces la semejanza es muy tenue, no menos real: en el Salmo de penitencia (pág. 106) "a los vientos subtiles" recuerda dos versos del rom. "Aquí entre la verde juncia": "No solo a los recios vientos, / mas a los aires sutiles" (n. $\left.{ }^{\circ} 14\right)$. El "Romance a la lección mortal de la belleza de la rosa" (pág. 110) se dirige a la flor con estas palabras: "reina coronada de oro, / te guardan picas de bronce"; el correlato gongorino, de 1609, es el romance "Esperando están

\footnotetext{
- Ya la menciona C. A. de la Barrera en su Catálogo. Cf. la edición de J. M.a Lope Toledo (Logroño, 1951).

10 Para las obras de Góngora remitimos al número que ostentan en la ed. de J. e I. Millé (Madrid, 1932).
} 
la rosa" (n. ${ }^{\circ} 61$ ), donde se lee: "Como a reina de las flores / guarda la ciñe fiel, / si son archas las espinas / que en torno de ella se ven" (en la ed. Millé arcas, por errata; las archas son un tipo de picas). En la Soledad del Gran Duque (pág. 149) dice a un ruiseñor: "Cometes, dulce lengua de las ramas, / más fugas con la voz que con la pluma"; Góngora se había reído de un matasiete con el mismo retruécano: "cuanto porque el español / en las lides que le mete / hace más fugas con él / que Guerrero en un motete" (rom. n. ${ }^{\circ}$ 35). Poco después aparece una "abeja ... argumentosa" (pág. 151), que ha volado desde el romance a Santa Teresa, a quien Góngora aplica la imagen: "Moradas, divino el arte / y celestial la materia, / fabricó, arquitecta alada, / si no argumentosa abeja” (n. ${ }^{\circ} 69$ ). Algo más abajo aparece el v. 312: "que restituye robos del ivierno", donde hubiera convenido anotar que sintetiza los vv. "iQué de robos han visto del invierno, / qué de restituciones del verano", iniciales de la Farmaceutria de Quevedo, publicada en las Flores pero atribuida al propio Espinosa en el Cancionero Antequerano, III, n. ${ }^{\circ} 101$. En v. 313 hay que corregir la anotación de López Estrada: pía de Juno alude, una vez más, a Góngora: "Ven Himeneo, y las volantes pías, / que azules ojos con pestañas de oro / sus plumas son, conduzgan alta diosa" (Soledades, I, 806-808); las tales pias son pavos reales, con cuyos colores se viste el prado, en el v. de Espinosa (cf. Obra en prosa, págs. 289 y 304, donde las notas lo señalan). En el Himno al Ángel Custodio del Duque (pág. 184), tras mencionar la gongorina raridad del viento (rom. $\mathrm{n} .^{\circ} 1$ ), se pregunta el poeta: "¿Diré de religión o de portentos? / De religión y de portentos digo". Hasta tal punto lo había impresionado la Fábula de Piramo y Tisbe: "¿Ebúrneos diré, o divinos? / Divinos digo, y ebúrneos" (vv. 407-8). Aun en el soneto al onomástico del Duque (pág. 189), el v. 8 "estrellas haces ver a medio dia" no deja de recordar otro pasaje gongorino: "Estrellas os hallan, / que mujeres destas / en medio del dia / hacen ver estrellas" (rom. n. ${ }^{\circ} 53$ ).

Pero es en la prosa donde la presencia del modelo se hace más continua y sorprendente. En el Pronóstico judiciario acusa al tiempo de "servir los postres a los principios, y juntar la punta con el pomo" (pág. 129); frase alusiva a cierto Gil que, desdeñado por Minguilla en el rom. 84 de Góngora, "imitar al babilonio / ya quería, y en su espada / buscar por la punta el pomo". Y cuando Espinosa vaticina que en "los caballeros motilones la biznaga será de anillo" (pág. 149), tiene presente la biznaga honrada no de una sino de dos letrillas gongorinas: "Que se precie un don Pelón / que se comió un perdigón / bien puede ser: / mas que la biznaga honrada / no diga que fue ensalada / no puede ser" (n. ${ }^{\circ}$ VII en la ed. de R. Jammes, Madrid, 1980; otro ejemplo en la $\left.\mathrm{n}^{\circ} \mathrm{XII}\right)$. Nada más empezar El perro y la Calentura dice el narrador que "embargué un paso a lo grullo" (pág. 159), y la nota recurre al Léxico del marginalismo para dar muy lejos del blanco: la frase evoca de 
nuevo a Píramo, quien en un pasaje ya recordado de la fábula gongorina (v. 398) se queda "pendiente en un pie a lo grullo", no porque grullo signifique nada en el lenguaje de germania, sino porque las grullas duermen sobre una pata. En la página siguiente añade Chorumbo: "Destruya Dios las lenguas mentirosas, que aun a Judas hacen fiesta con octava", como Góngora, cuando se arrepiente de celebrar "las fiestas de la corte, poco menos / que hacérselas a Judas con octava" (n. ${ }^{\circ}$ 395). También el "cósanme esta boca" de pág. 161 aparece tal cual en la Canción de Marinuño, v. 32 (n. ${ }^{\circ} 406$ ). En pág. 162 satiriza a los presumidos de linaje, que tienen "sangre, más que morcillas", lo mismo que el caballero chanflón del rom. 44 de Góngora: "Sangre, más que una morcilla, / honra, más que un paladin" "1.

Espinosa alaba "escribir con plumas de pavón, porque tienen ojos" (página 171); pero antes lo habia alabado Góngora: “... No es mi intento a nadie dar enojos, / sino apelar al pájaro de Juno: / gastar quiero de hoy más plumas con ojos / y mirar lo que escribo" (n.0 395). "Los mismos diablos no podrán meter paz en las cuchilladas de sus folladas" (pág. 182); tampoco podía hacerlo, en el romance de Góngora, el pobre Rengifo: "Un hidalgo introduciendo, / en las cuchilladas, paz, / de un follado incorregible,

11 Hay otras notas descarriadas u omitidas en las Obras en prosa: pág. 134, el Jordán se menciona porque se creía que tenía poder de rejuvenecer a quien se bañaba en él. En pág. 135 (pronóstico 16) privada de la conversación es retruécano por el doble sentido de privada. En pág. $139 \mathrm{el}$ pron. 1 remite a Lucrecio. En pág. 152 no se puede enmendar en este, porque se refiere a la tormenta, durante la cual los navegantes hacen votos que luego no cumplen. En pág. 165 el aires vola del impreso está bien: "Aires bola, aires tararira, kagaxón para kien me mira. Palavras ke deklaran plazer en el ke las dize" (Correas). El asotadas del texto en pág. 166 debe enmendarse en azotados. Pág. 168, en vago, 'en vacio'. La frase cuero estoy (pág. 170) no tiene que ver con estar en cweros. En la misma página a lo que se alude no es al hecho de que Midas tuviera orejas de burro, sino al curioso modo como se difundió el secreto. Pág. 171, el saludador es en especial el que curaba la rabia con saliva. En pág. 172, traer las piernas es retruécano que requiere explicación. Y todos los como de las frases exclamativas de págs. 172175 requieren acento. Es muy dudoso que el Cordero de pág. 178 tenga sentido obsceno: significa simplemente que San Juan, no Salomé, mostró a Cristo a quienes lo habían de matar (sobra, pues, la coma tras cabeza). El apóstol calabrés de pág. 186 es Judas, no una mezcla de vinos. Coyoles, pág. 209, no solo los hay en América sino en Andalucía; usa la palabra el Dr. Salinas. La frase referente a San Antón, pág. 216, se relaciona con la costumbre de llamar coche, es decir, cerdo, a quien eructaba. En pág. 245, la segunda línea de nota 35 se ha repetido por error. Pág. 316, n. 214, no debe de ser pertinente la acepción 'alejado' sino 'alargado' para luengo: otros barcos luengos aparecen en páginas 318 y 391. De los pinos dice Salcedo Coronel que "sirven principalmente ... para entenas de las naves o barcos luengos que se fabrican en Sevilla" (Soledades, fols. 299$300)$. Y el viajero Thomas Williams, en 1680 , anota que "en Sanlúcar hay una especie de barcos que llaman barcas lungas, los mejores veleros y los barcos más extraordinarios del mundo cuando hace viento" (cit. por P. Shaw, España vista por los ingleses del siglo XVII, Madrid, 1981, pág. 318). Pág. 319, “sementera de dientes es cosecha de hombres armados" no significa lo que dice la nota, sino que alude al mito de Jasón, quien sembró en Cólquide los dientes del dragón que guardaba el vellocino, y de ellos nacieron los espartos, o guerreros autóctonos. Pág. 341, n. 50 : la pretina del cielo es el zodiaco. 
/ puesto que mayor de edad" (n..$^{\circ} 73$ ). Los "cernicalos de uñas prietas ..." mencionados en pág. 185 son los mismos de un romance gongorino: " $\mathrm{El}$ moro, contemplativo, / a los de su dama vuela / como a los ojos del búho / cernícalos de uñas prietas" (n. $\left.{ }^{\circ} 21\right)$. La frase "Vine por beber de bruzas de estos fugitivos cristales y tomar residencia, a las varas de los albérchigos, de su oficio" (pág. 190) embebe (después de hacerlo en la Soledad del Gran Duque) la imagen jurídica de los tercetos gongorinos de 1609, que Espinosa despoja una y otra vez: "Sobre el aljófar que en las hierbas luce / o se reclina, o toma residencia / a cada vara de lo que produce" (n. $\left.{ }^{\circ} 395\right)$. En la misma página comenta la Calentura: "Solo uno en el mundo gongoriza, perdóneme el Antídoto y la escuela del señor Herrera ... He andado y visto tanto que puedo ayudar a vuestra merced con un grito", y esto último, para el lector iniciado, es otro guiño hacia Góngora, quien había dicho en un romance: "Y he de ser tan inhumano, / que a quien otra vez piadoso / ayudara con un grito, / acudiré con un soplo" (n. ${ }^{\circ} 33$ ). La extraña sentencia "Sobre un corcho anda la honra de los hombres" (pág. 195), referida a los chapines femeniles, solo se entiende si se recuerdan los versos de otro romance satírico: "El pie sobre corcho / (mirad qué firmeza), / mueve con buen aire / mi honra y la vuestra" (n. ${ }^{\circ} 53$ ). "Retínese el viejo de Malpica, y quiere que creamos que es milagro y no escabeche" (pág. 196); ya en su primera edición de las letrillas gongorinas (París, 1963, pág. 46), remitía R. Jammes a este paso de El perro y la Calentura para ejemplificar la difusión de la n. ${ }^{\circ}$ VII : "Que anochezca cano el viejo / y que amanezca bermejo / bien puede ser; / mas que a creer nos estreche / que es milagro y no escabeche / no puede ser." Todavía en el repaso a grupos sociales, pág. 211 , se encuentra esta denuncia: "Santa simple, aunque doble, no me bautices el bostezo por suspiro, para que sepa dónde te sientas", cuya fuente es la misma letrilla: "Que la viuda en el sermón / dé mil suspiros sin son, / bien puede ser, / mas que no los dé, a mi cuenta, / por que sepan dó se sienta, / no puede ser."

En las obras de carácter panegírico o cronístico sigue siendo Góngora el punto de referencia, sin más trabajo que incrustar sus propias formulaciones apenas adaptadas al nuevo contexto. "El majestuoso dosel" y el "déjate hallar" de pág. 244 vienen derechamente de la dedicatoria de las Soledades. "Tascando el freno de oro", pág. 304, procede en cambio de la dedicatoria del Polifemo: "Tascando haga el freno de oro cano / del caballo andaluz la ociosa espuma.". La "velera paloma" que en pág. 334 "vuela por las azules ondas marinas. Pues no trae oliva" ha servido antes para rescatar al joven desdeñado que habita una isla desierta en el romance de Góngora: "Cuando velera paloma, / alado si no bajel, / nubes rompiendo de espuma / en derrota suya un mes, / le trajo, si no de oliva ..." (n. 70). Más adelante Espinosa dice al Duque: "Gozabas el día desde su nacer, sin hurtar las fábricas veci- 
nas del cielo, las que dudan los poetas si son torres o estrellas" (pág. 338); pero los poetas son el de siempre: "Aquellas que los árboles apenas / dejan ser torres hoy -dijo el cabrero" de las Soledades, I, 212-213. "Más se implica el ave aleando en la liga" (pág. 348) es una frase de apariencia inocente que también remite a $L a T$ isbe, cuya heroina va, cual avecilla, "a implicarse desalada / en la hermana del engrudo", es decir, en la liga (vv. 443-4). "El sobresalto echó grillos de hielo" a la gente (pág. 350) cuando se supo que el inglés atacaba Cádiz; otro tanto le ocurre a la Colmeneruela en el baile de Góngora: "Saludóla el caballero, / cuyo sobresalto, al pie / grillos le puso de hielo" (n. 62). De este mismo romance, los "muchos siglos de hermosura / en pocos años de edad" se convierten en los "cuarenta siglos de socorro en cuarenta dias de cuidado" que el Duque apercibió contra el ataque (pág. 350) ${ }^{12}$. En pág. 352 encontramos de nuevo un erotema que tiene igual origen que el del Himno al Ángel Custodio (cf. supra): "¿Llamaréla demasía o fineza? Llámola fineza y demasía." La frase "Pues avisando el edificio con estremecimientos, ¿qué aguardamos?” (pág. 355) podría remitir directamente a Séneca (Epist. XXX, 2), si no fuese tan próxima en la forma a otra de Góngora: “¿Qué prudencia, del polvo prevenida, / la ruina aguardó del edificio?" (n. ${ }^{\circ}$ 373). El Duque prepara su propio sepulcro: "De aromáticos leños construyes nido, en que, fénix, te reserves”, dice su cronista (pág. 357), aunque con palabras prestadas de un soneto que Góngora había dedicado a don Rodrigo Calderón: "Ser pudiera tu pira levantada / de aromáticos leños construida, / oh Fénix en la muerte ..." (n. ${ }^{\circ} 365$ ). Hasta para designar a los pájaros se echa mano del mismo diccionario: "el vulgo lego de las aves" (pág. 360) traspone a la región del aire "el vulgo de esotras yerbas" del romance 61, o el "vulgo nadante digno apenas / de escama", de Soledades, II, 415-6. Por último, en el Panegírico a Antequera dice que los toros "que en tus sotos, con dos llamas, consultan la soledad, y en la no mandada (?) grama pacieron el coraje, cuando escarban la arena de la plaza señalan sepulturas" (pág. 421); Góngora les había sugerido algo así a los toros de Jarama cuando viniesen a estrenar la Plaza Mayor de Madrid: "Que salgan de los toriles / entre feroces y tibios, / sin bramar a lo casado / ni escarbar a lo gallino, / mas si escarbaren, que sea / para dar luz al abismo, / o sepulcros a los muertos / que no se comieren vivos" (rom. n. ${ }^{\circ}$ 78). El Panegírico a Antequera termina con varias alusiones ya señaladas por Gates, pues para elogiar la patria chica, ¿qué mejor referente podía desear el nostálgico poeta que el bucólico paisaje de las Soledades gongorinas? Con esa y las demás citas no solo pagaba tributo al mayor lírico de su tiempo y de su tierra, que había

12 Aun el dóctor Alderete, que firma una aprobación del Panegírico a Antequera, no puede privarse de prolongar la antítesis: "Nos da muchos siglos de discreción en una hora de escrito" (pág. 409). 
iluminado su vida colaborando en las Flores y habia vinculado un poema perfecto a la casa de Medina Sidonia, sino que convertia su propia obra en un mosaico donde el diseño era suyo, y el brillo, de Góngora. Así adquieren sentido, a nuestro juicio, los aspectos formales que nos ha parecido útil destacar en ella. Como dijo Espinosa Medrano ante un verso del Polifemo incrustado en un soneto anónimo: " ¿ No advertís ya que en todo el soneto el quarto verso brilla por astro de todo él? Pues por tal le puso alli quien devidamente estimava sus esplendores" ${ }^{13}$.

13 Apologético en favor de D. Luis de Góngora, ed. V. García Calderón, Revue Hispanique, LXV, 1925, pág. 476. 